Int. J. Electrochem. Sci., 14 (2019) 11465 - 11479

International Journal of

ELECTROCHEMICAL

SCIENCE

$\underline{\text { WwW.electrochemsci.org }}$

\title{
Correlations between the Growth Mechanism and Corrosion Resistance of Plasma Electrolytic Oxidation Coatings on AZ31B Magnesium Alloy
}

\author{
Yujie Wang*, Peng Zhang, Yunhui Du, Weiyi Zhang and Haitao Cao \\ School of Mechanical, Electronic and Control Engineering, Beijing Jiaotong University, Beijing \\ 100044, China \\ *E-mail: yujie_wendy@126.com
}

doi: $10.20964 / 2019.12 .18$

Received: 9 July 2019 / Accepted: 6 September 2019 / Published: 29 October 2019

In the present work, plasma electrolytic oxidation (PEO) coatings with different microstructures were fabricated on AZ31B magnesium alloy. The thickness, morphology, phase composition and elemental distribution of the obtained coatings were characterized by X-ray diffraction (XRD), scanning electron microscopy (SEM), and energy dispersive spectroscopy (EDS). The corrosion behaviors of PEO coatings were measured by potentiodynamic polarization curves and electrochemical impedance spectroscopy (EIS). The results show that a composite dielectric coating is obtained with similar contents of $\mathrm{MgO}$ and $\mathrm{MgF}_{2}\left(\mathrm{MgO}-\mathrm{MgF}_{2}\right.$ coating). During the discharge in the PEO process, by taking advantage of these two dielectrics' electrical performance and physical properties to influence dielectric breakdown, and utilizing the effect of blocking and heating in the two dielectrics, the molten materials ejected from the discharge channels decrease and more remains in the discharge channels; therefore, the thickness of the compact layer of the $\mathrm{MgO}-\mathrm{MgF}_{2}$ coating increases. Consequently, the coating thickness is approximately $3.5 \mu \mathrm{m}$, which is twice that of the coating with $\mathrm{MgO}$ as the main component $(\mathrm{MgO}$ coating). Furthermore, the results of electrochemical experiments demonstrate that the corrosion potential of the $\mathrm{MgO}-\mathrm{MgF}_{2}$ coating is $0.91 \mathrm{~V}$ larger than that of the $\mathrm{MgO}$ coating. As evaluated by EIS, the impedance of the inner compact layer is increased by more than 5 times from $7.652 \times 10^{5} \Omega \cdot \mathrm{cm}^{2}$ for the $\mathrm{MgO}$ coating to $4.933 \times 10^{6} \Omega \cdot \mathrm{cm}^{2}$ for the $\mathrm{MgO}-\mathrm{MgF}_{2}$ coating. These results indicate that the growth mechanism of the $\mathrm{MgO}-\mathrm{MgF}_{2}$ coating can increase the thickness of the compact layer and effectively improve the corrosion resistance.

Keywords: Dielectric breakdown; Dielectric constant; Compact layer; Growth mechanism; Corrosion resistance

\section{$\underline{\text { FULL TEXT }}$}


(C) 2019 The Authors. Published by ESG (www.electrochemsci.org). This article is an open access article distributed under the terms and conditions of the Creative Commons Attribution license (http://creativecommons.org/licenses/by/4.0/). 